\title{
Una especie nueva de Stegnosperma (Phytolaccaceae) del suroeste de Puebla, México
}

\author{
Francisco González-Medrano ${ }^{1}$ y Rosalinda Medina Lemos ${ }^{2}$
}

\begin{abstract}
RESUMEN. Stegnosperma sanchezii Medrano y Medina (Phytolaccaceae) se describe como especie nueva del suroeste de Puebla. Se encuentra relacionada con Stenogsperma watsonii D.J. Rogers, de la que difiere en hábito, forma y pubescencia de la hoja y en el margen revoluto. Actualmente la nueva especie se conoce sólo de la localidad tipo y sitios cercanos.
\end{abstract}

ABSTRACT. Stegnosperma sanchezii Medrano \& Medina (Phytolaccaceae) is described from southwestern Puebla. Its closest relationship appears to be with Stegnosperma watsonii D.J. Rogers, from which it differs in habit, form and pubescence of the leaf and in the revoluted margin. This species is known at present only from the type locality and nearby sites.

Como parte de un estudio ecológico de la vegetación en el suroeste de Puebla se recolectó una planta del género Stegnosperma Benth., que después de analizarla resultó ser una especie nueva.

\section{Stegnosperma sanchezii Medrano \& Medina sp. n. (fig. 1)}

S. watsonii D.J. Rogers., affinis, differt habitu fructicoso et foliis pilosis oblanceolato-spathulatis margine revoluto.

TIPO: PUEBLA: Municipio de Molcaxac: $2 \mathrm{~km}$ al W de Molcaxac, sobre la brecha que va de Molcaxac a San Juan Atzompa, en colinas calichosas orientadas al N, formando parte del matorral xerófilo, con Dalea, Calliandra, Cynanchum, Gymnosperma, Asclepias, etc., altitud 1820 m, 6 IV 1982, F. González Medrano 12421, con R. Medina L. y A. Valiente B. (HOLOTIPO: MEXU; ISOTIPOS pendientes de distribuir.)

PARATIPOS: PUEBLA: Municipio de Atoyatempan: Cañada de Acatzitzimitla, en la parte alta de la cañada, ladera occidental, altitud $1850 \mathrm{~m}, 6$ VI 1982, F. González Medrano 12623 (MEXU); Cañada de Acatzitzimitla, en la parte media de la barranca,

${ }_{1}^{1}$ Departamento de Botánica, Instituto de Biología, Universidad Nacional Autónoma de México, Apdo. Postal 70-233, 04510 México, D.F.

${ }^{2}$ Becario del Programa de Formación de Personal Académico, UnAM.

González-Medrano F, Medina-Lemos R. 1984. Una especie nueva de Stegnosperma (Phytolaccaceae) del suroeste de Puebla, México. Boletín de la Sociedad Botánica de México 46: 37-41. 
BOLETÍN DE LA SOCIEDAD BOTÁNICA DE MÉXICO, Núm. 46, 1984

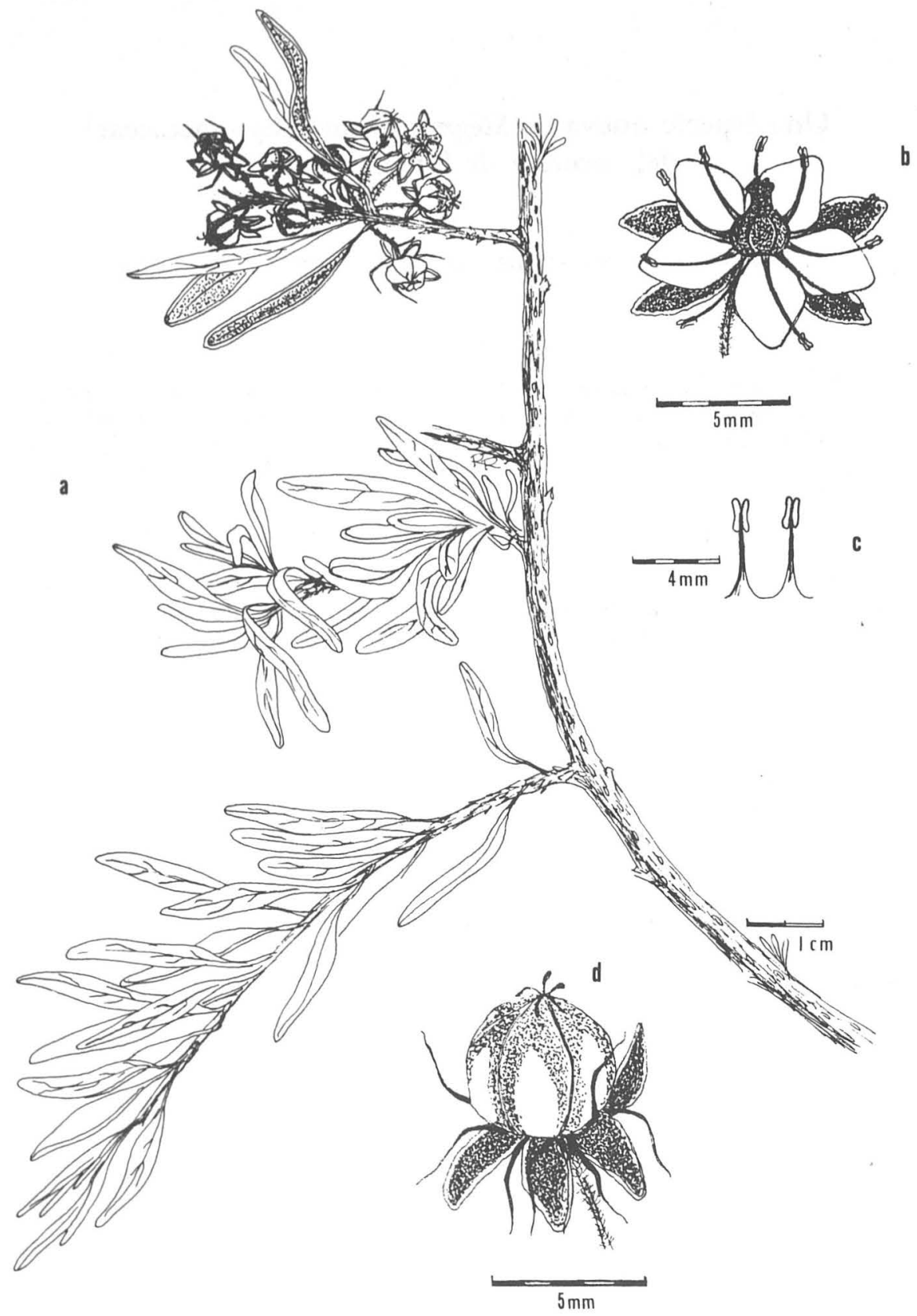

Fig. 1. Stegnosperma sanchezii. Medrano y Medina. a. Rama con frutos; b. Flor; c. Estambres; d. Fruto. 
cerca de los cursos de agua, en la ladera occidental, 6 VI 1982, F. González Medrano 12626 (MEXU); Cañada de Acatzitzimitla, 28 VI 1982, F. González Medrano 12703 (MEXU). Municipio de Molcaxac: Puente de Dios, $2 \mathrm{~km}$ al W de Molcaxac, laderas calizas cerca del río, 28 VI 1982, F. González Medrano 12738, con Dolores Nava y Beatriz González (MEXU). Municipio de San Juan Atzompa: cañada en las faldas de la Sierra Tzentzo, después de San Juan Atzompa, al NW de Molcaxac, 19 XII 1982, R. Medina L. 405, con A. Valiente B. y R. Peralta y F. (MEXU).

Arbusto erecto, de 1-2.5 m de altura. Tallo café oscuro, ramas jóvenes tomentosas a glabrescentes con la edad, con pelos simples, ramas viejas con lenticelas de $0.5-2.3 \mathrm{~mm}$ de largo; entrenudos de las ramas jóvenes, en algunos individuos, muy cortos, dando así la apariencia de hojas verticiladas. Hojas alternas, simples, enteras, pecioladas; lámina oblanceolada u oblanceolado-espatulada, de $0.5-2.5 \mathrm{~cm}$ de largo y $0.2-0.6 \mathrm{~cm}$ de ancho, verde claro cuando es joven, margen marcadamente revoluto y piloso, haz y envés densamente vellosos; pecíolo rojo de $0.2-0.5 \mathrm{~cm}$ de largo, pubescente. Inflorescencias en racimos terminales, a veces con el eje tan corto y los pedicelos tan largos que parecen corimbos, de 1-2 cm de largo, con 1-15 flores, pedicelos de $0.6-1 \mathrm{~cm}$, pilosos; brácteas triangulares a obtriangulares, de 1-2 mm de largo. Sépalos 5, oblanceolados, de 2.8-5.0 mm de largo y 1.8-2.3 mm de ancho, verdes, con márgenes membranosos blancos en la flor y verderojizos con márgenes membranosos rojos en el fruto, persistentes. Pétalos 5 , de $3 \mathrm{~mm}$ de largo y $1.8-2 \mathrm{~mm}$ de ancho, con los dos tercios superiores anchamente trulados y el inferior angostamente atenuado, blancos, caedizos. Estambres 10, diplostémonos, en un anillo perígino de $0.8-1 \mathrm{~mm}$ de diámetro, connatos, alternando con los lóbulos del cáliz; filamentos subulados de 2.6-4 mm de largo, persistentes en el fruto; anteras 10, de color amarillo-crema, elípticas biloculares, dorsifijas, introrsas, de 0.9-1.2 mm de largo. Ovario de 5 carpelos, súpero, sésil, anchamente ovoide y subanguloso, glabro, óvulos 1 por cavidad, basales, anfítropos; estilo reducido; estigma con 5 ramificaciones, de 1-1.5 mm de largo y 0.5-0.7 mm de ancho, subulados, reflejos. Fruto capsular, globosoanguloso, de $5 \mathrm{~mm}$ de largo y $5(6) \mathrm{mm}$ de ancho, con 5 valvas carinadas en el interior, coriáceas, color púrpura, con marcas verdosas de los sépalos en las valvas. Semillas 5, madurando generalmente 3 , de 2.0-3.5 mm de largo y $2.0-2.5 \mathrm{~mm}$ de ancho, negras, brillantes, cubiertas casi totalmente por el arilo color magenta en las semillas maduras y blanco en las jóvenes, de aspecto esponjoso; perispermo harinoso.

El nombre de esta especie está dedicado al profesor Óscar Sánchez, autor de La flora del Valle de México, en reconocimiento a su labor como maestro.

\section{DisCUSIÓN}

Las tres especies de Stegnosperma Benth. antes conocidas viven en o cerca de las dunas costeras (Gilmartin y Neighbours, 1982) y sólo S. cubense A. Rich. se había recolectado tierra adentro. S. sanchezii se recolectó en la región central del país, lejos de las costas (fig. 2), viviendo sobre terrenos calichosos y someros, o bien creciendo sobre aquellos derivados de caliza, y aun en los suelos de coluvión, formando parte de los matorrales xerófilos al oeste de Molcaxac, Puebla.

En el material estudiado se encontró una variación en el tamaño de la hoja y en el carácter revoluto; se sugiere que esto quizá se deba a la diferencia de disponibilidad 
BOLETÍN DE LA SOCIEDAD BOTÁNICA DE MÉXICO, Núm. 46, 1984
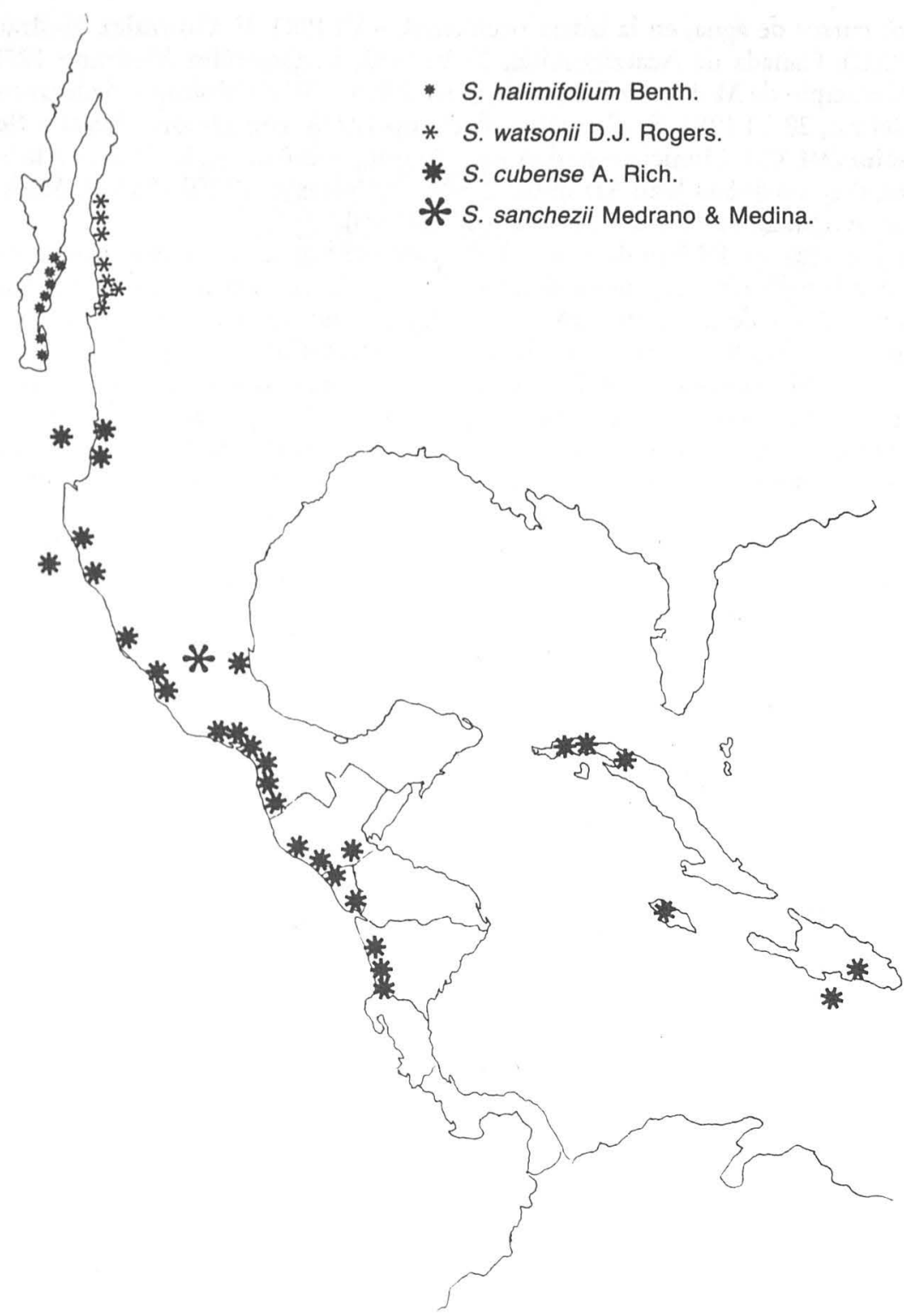

Fig. 2. Distribución geográfica del género Stegnosperma en México y áreas adyacentes (Gilmartin y Neighbours, 1982; Rogers, 1949). 
TABLA 1. Características que diferencian las cuatro especies de Stegnosperma

\begin{tabular}{|c|c|c|c|c|}
\hline Carácter & S. halimifolium & S. watsonii & S. cubense & S. sanchezii \\
\hline Forma de vida & arbusto & $\begin{array}{l}\text { trepadora } \\
\text { leñosa }\end{array}$ & $\begin{array}{l}\text { trepadora } \\
\text { leñosa }\end{array}$ & arbusto \\
\hline Forma de hoja & $\begin{array}{l}\text { obovadas a } \\
\text { orbiculares }\end{array}$ & $\begin{array}{l}\text { elípticas a } \\
\text { espatuladas }\end{array}$ & orbiculares & $\begin{array}{l}\text { oblanceoladas } \\
\text { a espatuladas }\end{array}$ \\
\hline Margen de la hoja & involuto & involuto & involuto & revoluto \\
\hline $\begin{array}{l}\text { Pubescencia de la } \\
\text { hoja }\end{array}$ & ausente & ausente & ausente & piloso-vellosa \\
\hline $\begin{array}{l}\text { Núm. de estigmas y } \\
\text { carpelos }\end{array}$ & 5 & 5 & 3 & 5 \\
\hline $\begin{array}{l}\text { Núm. de valvas en } \\
\text { el fruto }\end{array}$ & $5(4-3)$ & 5 & $3(4)$ & 5 \\
\hline
\end{tabular}

de agua, ya que las más desarrolladas y menos revolutas se encontraban en sitios más protegidos y cerca de cuerpos de agua.

Por sus características $S$. sanchezii parece estar más relacionada con $S$. watsonii D.J. Rogers, que con cualquiera de las otras especies (tabla 1).

Agradecimientos. Agradecemos al doctor Fernando Chiang la elaboración de la diagnosis latina.

\section{LITERATURA CITADA}

Gilmartin, A.J. y M.L. Neighbours. 1982. Variability within Stegnosperma halimifolium Benth. (Phytolaccaceae). Southw. Natur. 27(1):63-72.

Rogers, D.J. 1949. Stegnosperma. A new species and a generic commentary. Ann. Missouri Bot. Gard. 55:294-364. 